\title{
A crise do normativismo jurídico e a exigência de uma normatividade concreta. $\left({ }^{*}\right)$
}

\author{
Miguel Reale. \\ Catedrático de Filosofia de Direito na Facul- \\ dade de Direito da Universidade de São Paulo.
}

1 - O problema da normatividade como elemento essencial da experiência jurídica é dos que mais têm suscitado distinções radicais na Filosofia do Direito contemporânea. Isto não obstante, talvez assista razão a Karl Olivecrona quando assevera que, inexplicàvelmente, se tem atribuído pouca importância a uma precisa determinação do conceito de norma (L'imperativo della legge, "separata" da Rev. Jus, Dezembro, 1954, fasc. IV, pág. 542.).

Se, de um lado, a Escola do Direito Puro de Hans Kelsen reduz o Direito a um sistema escalonado de normas, segundo uma estrita exigência formal, de outro lado, há jurisfilósofos que o concebem precìpuamente em têrmos de experiência ou de conduta, quer sejam estas expressões empregadas empìricamente, à maneira dos "juristas sociólogos", quer segundo um enfoque transcendental ou axiológico, como nos estudos de Giuseppe Capograssi ou de Carlos Cossio. Entre êsses dois extremos do Direito-norma e do Direito-conduta, entre a racionalidade abstrata correspondente à primeira concepção e a exigência de concreção revelada na segunda, desenvolve-se uma série variegada de

(*) Trabalho apresentado ao IV Congresso Interamericano de Filosofia (II da Sociedade Interamericana de Filosofia) realizado em Washington, de 8 a 14 de Julho de 1957. 
posições doutrinárias, as quais correspondem às duas tendèncias que atuam poderosamente na evolução do Direito: uma tendência no sentido do primado da ordem e da certeza, muito embora com sacrifício de certas qualidades ou características peculiares a cada uma das ocorrências da vida social; uma outra, preocupada com o conteúdo social do Direito, até ao ponto de recorrer a fôrças intuitivas oú a-racionais, correndo o risco de afrontar o incerto e o mutável, desde que possa captar, em sua plenitude, o fluxo do jus vivens.

Não resta dúvida que, em nossa época, como reflexo da crise de valores que se opera na civilização do Ocidente, inclusive pelo impacto da ciência sôbre a sociedade, alargando as bases de participação humana aos "bens de vida" proporcionados pela técnica, há um desajuste ou um conflito entre as condições existenciais e as normas jurídicas vigentes. A chamada "crise do Direito", que não é senão um aspecto relevante da crise geral da cultura contemporânea, apresenta, a meu ver, um grave sintoma, que é a perda de confiança nas soluções normativas, ou por outras palavras, o crescente predomínio do emocional ou do intuitivo sôbre aquela exigência fundamental de racionalidade que me parece essencial à concepção democrática do Direito.

Seria, evidentemente, absurdo, a esta altura do século, pretender fazer tábula rasa das preciosas contribuições dos mestres da Jurisprudência sociológica ou do Sociologismo jurídico, como Eugen Ehrlich e Roscoe Pound; dos novos rumos apontados para a exegese e a aplicação do Direito, pela escola da "livre investigação" de François Gény ou do movimento do "Direito livre"; dos ensinamentos de Oliver Wendell Holmes sôbre "a vida real do Direito" em cotejo com as estruturas lógico-formais; dos reclamos em prol de uma "Jurisprudência de interêsses", ou por uma "Jurisprudência axiológica"; da penetrante análise dos motivos determinantes da vida jurídica, feita pelos mentores do "realismo americano", assim como da mais recente postulação 
de Recaséns Siches no sentido de uma "Lógica do humano e. do razoável", e de muitas outras expressôes de uma vontade comum de trazer corajosamente à plena consciência do jurista as fôrças vivas que atuam no bojo da experiência histórica do Direito.

O problema que me proponho é bem outro. Longe de repelir as críticas movidas à Jurisprudência conceitual, o que me pergunto é se tais críticas atingem tôdas as formas de normativismo jurídico ou se, ao contrário, não são elas procedentes apenas com referência a uma concepção particular de normatividade, à que se poderia denominar "normatividade jurídica abstrata". No fundo, êste reconhecimento é feito por alguns dos mentores da revisão crítica da Jurisprudência tradicional, mas nem sempre envolvendo o problema essencial de um novo conceito de norma mais correspondente às exigências de concretitude reclamada pela Jurisprudência atual.

2 - A contraposição ou a antítese às vêzes afirmada entre a "normatividade jurídica" e a "vida real do Direito" só tem sentido enquanto nos conservamos apegados a um conceito abstrato de norma como simples "juízo lógico", diversamente qualificado como sendo de natureza hipotética, disjuntiva ou conjuntiva, etc.

A norma jurídica é sim um juizo lógico, mas é bem mais do que isto: o enlace lógico-normativo, a meu ver, não é senão o modo de significar uma realidade humana distinta, com o sentido do valor ou dos valores que the correspondem, ou por outras palavras, o juizo lógico é um "suporte ideal" graças ao qual uma dada porção da "experiência humana" é qualificada especificamente como “experiência jurídica”. (Sôbre a compreensão do "juízo lógico-normativo" como "suporte ideal" da norma jurídica, v. minha - Filosofia do Direito, São Paulo, 1953, vol. I, págs. 213 e segs.).

Conceber a norma juridica como simples "proposição normativa", - excepção feita para os objetivos restritos da Lógica Jurídica formal, que evidentemente não cuida 
senão de um aspecto da normatividade, - equivale, eme primeiro lugar, a conceber a Jurisprudência como uma ciência não normativa e, de outro, em admitir que uma proposição normativa possa ser "jurídica" sem se referir necessàriamente às condições "fático-axiológicas", objeto de sua significação. Daí poder-se dizer, sem fôrça de expressão, que o Direito é a norma e mais a situação normada. e que, a rigor, esta distinção mesma deve ser entendida com cautela, pois a norma, sòmente enquanto proposição lógica, pode ser concebida sem envolver a realidade por ela significada. O Direito é, em suma, intrìnsecamente normativo. É a razão pela qual, apesar de tôdas as restrições que têm sido feitas ao normativismo jurídico, os chamados juristas práticos, os advogados e os juízes, mantêm-se, em geral, fiéis a uma atitude normativista, vendo nas regras do Direito não apenas um enunciado de ordem lógica, mas também a exigência moral de um comportamento ao qual se ligam prèviamente certas consequências, previstas estas genèricamente, mas suscetiveis de serem determinadas "in concreto", segundo a justa aspiração de uma adequação cada vez maior entre a norma e cada caso. ocorrente.

Acresce que até mesmo os jurisfilósofos de formação anti-normativista acabam renovando todos os problemas postos pela normatividade quando se vêem deante das questões relativas à interpretação e à aplicação do Direito.

O maior equívoco que me parece existir, por conseguinte, nesta matéria, consiste em pensar a normatividade em termos de generalidade abstrata. Poderiamos dizer que a visão tradicional da norma juridica, - contra a qual se volveram as críticas acima lembradas, implica em apresentá-la como

a) um enunciado de uma classe de comportamentos possíveis;

b) dotado de uma validade lógica própria; 
c) que implica na obrigatoriedade de um: comportamento correspondente ao modêlo proposto;

d) desprendido ou desligado tal modêlo dos pressupostos fáticos e axiológicos que condicionaram a sua gênese;

e) assim como também indiferente a fatos e valores supervenientes.

Dentro desta concepção, uma vez emanada a regra pelo legislador, ou consagrada que seja pela jurisdição ou pelo costume, ela passa a valer como sintese conceitual. Julga-se que será bastante interpretá-la em sua significação formal plena, afim de que, mediante um simples procedimento de subsunção lógica, ela possa qualificar os fatos particulares enquadrados na órbita de sua incidência. Pensada, assim, a norma como um termo abstrato, ou por outras palavras, como um "modêlo", do qual deveriam defluir silogisticamente consequências adaptáveis às infinitas vicissitudes da vida social, foi fácil demonstrar o equívoco da alegada plenitude lógica do ordenamento jurídico, máxime com a crescente ruptura verificada entre a realidade social-econômica e as estruturas jurídico-normativas, as leis, os regulamentos, os precedentes judiciais, as normas costumeiras, etc. A vida real e concreta irrompeu violentamente, pondo à mostra a inanidade de conceber-se as sentenças ou as decisões administrativas como meros silogismos, nos quais a norma jurídica funcionaria ‘omo premissa maior de uma conclusão inevitável, ou como profecia daquilo que os Tribunais haveriam de decidir. Fsta é hoje uma observação que representa um ponto quase pacífico entre os filósofos de Direito, e que tende a ganhar também. terreno entre os mestres de Direito Processual.

3 - O que me parece, no entanto, excessivo é inferir-se das críticas acima apontadas, a condenação a todo e qual- 
quer normativismo jurídico, sem as restringir ao campo do normativismo abstrato. Não valerão tais críticas, com efeito, se ao contrário, concebermos a norma jurídica como:

a) um enunciado de uma classe de comportamentos possiveis;

b) dotado de uma validade lógica interna no seio do ordenamento jurídico vigente;

c) implicando na obrigatoriedade de um comportamento correspondente ao modêlo proposto;

d) sempre em função dos fatos e dos valores que o condicionaram originàriamente;

e) bem como de fatos e de valores supervenientes.

Na concepção do "normativismo abstrato", a validade da regra é "per se stante", de maneira que, por mera inferência lógica, a ela devem se conformar dadas realidades particulares: a norma, como tal, é o termo lógico conclusivo de um processo em sí mesmo cerrado e lògicamente imutável, até e enquanto outro enunciado lógico não o venha substituir, pela via normativa da revogação formal. Emanada a norma e enquanto esta se mantém em vigência, o que pode ocorrer são fatos e experiências axiológicas, correspondentes ou não ao esquema previsto: a juridicidade ou não decorrerá, por isto, do ajuste ou do desajuste entre o evento concreto e o enunciado da regra "in abstracto".

Em uma concepção de "normativismo concreto", ao contrário, exatamente porque a norma não é uma simples estrutura lógico-formal, ou um modêlo, mas prevê e envolve necessàriamente o momento futuro de uma ação concreta do homem, é necessário distinguir:

$\left.1 .^{\circ}\right)$ entre o "juízo-lógico", (o suporte ideal mediante o qual se expressa algo) e o "valor" expresso pelo juízo: suporte lógico e valor for- 
mam, em seu conjunto unitário, a norma jurídica, que, dêsse modo, não pode ser reduzida a um de seus dois elementos componentes.

$\left.2 .^{\circ}\right)$ entre a validade da "norma jurídica", examinada em sí mesma, - como, digamos assim, um anel destacado de uma corrente, ou uma conta desligada do rosário, - e a sua validade inserida no complexo do sistema ou do ordenamento.

Como se vê, a Lógica Jurídico-formal, - que não é senão a Lógica mesma enquanto tem por objeto estruturas significativas da experiência jurídica, - tem um alcance restrito, não satisfazendo senão parcialmente às exigências metódicas da Ciência Jurídica: ela esclarece rigorosamente a estrutura do juízo de "dever ser" ou da proposição normativa, mas não envolve, nem poderia envolver, o momento decisivo da normatividade, que é o da sua atualização como conduta, isto é, como comportamento do juiz, do administrador, dos indivíduos e dos grupos a que ela destina.

4 - Isto pôsto, dadas as conexões existentes entre "realidade" e "normatividade" (e um mestre brasileiro, João Mendes Júnior, já afirmou com razão que não há norma jurídica sem realizabilidade) torna-se necessário partir da "nomogênese jurídica" para esclarecer os problemas da sua "interpretação" e "aplicação".

Penso que a "teoria tridimensional do Direito", tal como a tenho exposto (Cf. - Filosofia do Direito - São Paulo, 1953 - Horizontes do Direito e da História, São Paulo, 1956) pode trazer alguma luz à compreensão do problema.

Devo, de início, observar que a tridimensionalidade não deve, a meu ver, ser concebida como uma simples descrição da experiência jurídica em termos de fato, valor e norma. Juristas filósofos das mais variadas tendências, como por exemplo Gustavo Radbruch, Wilhelm Sauer, Roscoe Pound, Julius Stone, Jerome Hall, Recasens Siches, Carlos Cossio, ou Garcia Máynez, acordam em reconhecer a exis- 
tência dos três fatores. O que mais importa é esclarccer a natureza da correlação existente entre aquêles três fatôres, para determinar o nexo que os liga ou os implica entre si, o que só será possível colocando-nos perante a normatividade como uma expressão da experiência histórica do homem. A realidade do Direito, - não é demais declará-lo em face de tantas tendências no sentido de considerá-lo de maneira estático-formal, — é uma realidade essencialmente histórica, ou, mais precisamente, histórico-cultural, de sorte que o "processus" é a primeira categoria da realidade jurídica. Não há, pois que buscar uma realidade jurídica subjacente, que seria dotada de três dimensões ou facetas, como se se tratasse de algo natural ou corpóreo. o Direito, em suma, não é senão o processo mesmo de integração dos três fatôres acima discriminados, não podendo ser reduzido ao fato da "conduta em sua interferência intersubjetiva" como pretende Carlos Cossio. Sôbre a posição dêste jusfilósofo argentino perante a concepção tridimensional do Direito, v. in "La Ley" de 12-6-950, o estudo "Las actitudes filosoficas de la Ciencia Jurídica", no qual se olvida que, na "dialética da implicação e da polaridade", tal como a exponho, a tensão fato-valor-norma corresponde ao desenvolvimento do Espírito mesmo enquanto se objetiva em "bens de cultura", entre os quais se situa o "bem jurídico", ou seja, a realidade jurídica como experiência histórico-cultural.

Dêsse modo, se algum mistério existe no processar-se do Direito, como contraste e implicação perene de situações fáticas e exigências ideais, suscitando progressivas e renovadas "integrações normativas", tal mistério é o do próprio Espírito humano em suas projeções históricas, assim como de seu significado transcendental e universal em relação ao que històricamente se atualiza.

Daí a consequência de que a realidade do Direito só pode ser justamente compreendida como um processo em que os três elementos (fato, valor e norma) se implicam e se integram em uma unidade dialética: trata-se de três: 
dimensões, ou melhor, de três momentos, de uma experiência social de natureza bilateral-atribuitiva, una em sua essência e desenvolvimento.

Para esclarecer êste meu modo de ver, observemos o que se passa quando surge uma norma juridica qualquer. Tôda norma jurídica corresponde a um momento culminante de um conjunto de fatôres: há, em primeiro lugar, um "complexo de exigências axiológicas", que dá lugar à nova norma, alterando ou substituindo as normas já existêntes; tal "complexo de exigências axiológicas" não opera "in abstato", é óbvio, mas condicionado a um "complexo de circunstâncias fáticas". É dessa correlação fático-axiológica que se origina a norma ou um "complexo de normas".

As exigências axiológicas podem ser as mais diversas, distribuindo-se através de uma escala de tendências de ordem espiritual, moral, intelectual, econômica, etc. Por outro lado, através da história, e em função do meio social em que o Direito é vivido, as condições fáticas igualmente variam com maior ou menor intensidade e extensão. Entre fato (ou "complexo de situações fáticas") e valor (ou "complexo de exigências axiológicas") existe uma permanente tensão. Às vêzes, chega a haver aberto contraste, o que tudo se torna sobremaneira perturbador quando se pensa que os mesmos valores podem dar lugar a reações psicológicas ou a "experiências estimativas" contrastantes ou opostas.

E claro que, deante de um contraste ou conflito entre valores e fatos, ou mesmo deante de um conflito entre múltiplas atitudes estimativas possíveis perante um único valor, que esteja històricamente incidindo em dado meio. social, nem tôdas as vias podem preponderar juridicamente. Nada mais incompatível com o Direito do que a incerteza, a carência de uma diretriz segura: o Direito responde, preliminarmente, ao desejo que o homem tem de fugir à dúvida, mais pungente no plano moral da ação do que no plano intelectual da especulação pura. 
Em face de uma situação imprevista, por exemplo, como uma guerra, uma revolução, ou um cataclisma, se as normas jurídicas são insuficientes, e tal insuficiência se revela, pondo a exigência de novas vias disciplinadoras do comportamento social, um caminho é escolhido, prontamente, sem maior demora. Óra, o que ocorre nêsses casos extremos, verifica-se tôda vez que uma norma jurídica surge: pode haver mais estudo e meditação, maior ou menor possibilidade de escolha, mas, em um dado momento, é mistér não protelar a opção. Uma opção se impõe, e tôda vez que se escolhe uma via, sacrificam-se tôdos os demais caminhos possíveis. Dentre os várioos projetos de lei em debate em um Parlamento, por exemplo, a respeito de um dado assunto, por mais que se procrastine, chega - momento do fiat lex, átimo culminante de uma decisão. É êste o momento do Poder.

Poder-se-ia talvez representar êste processo recorrendo ao símile (fig. infra) de um raio luminoso (impulsos e exigências axiológicas) que, incidindo sôbre um prisma (o multifacetado domínio dos fatos sociais, econômicos, técnicos, etc.) se refracta em um leque de "normas possiveis", uma das quais apenas se converterá em "norma jurídica", dada a interferência do Poder.

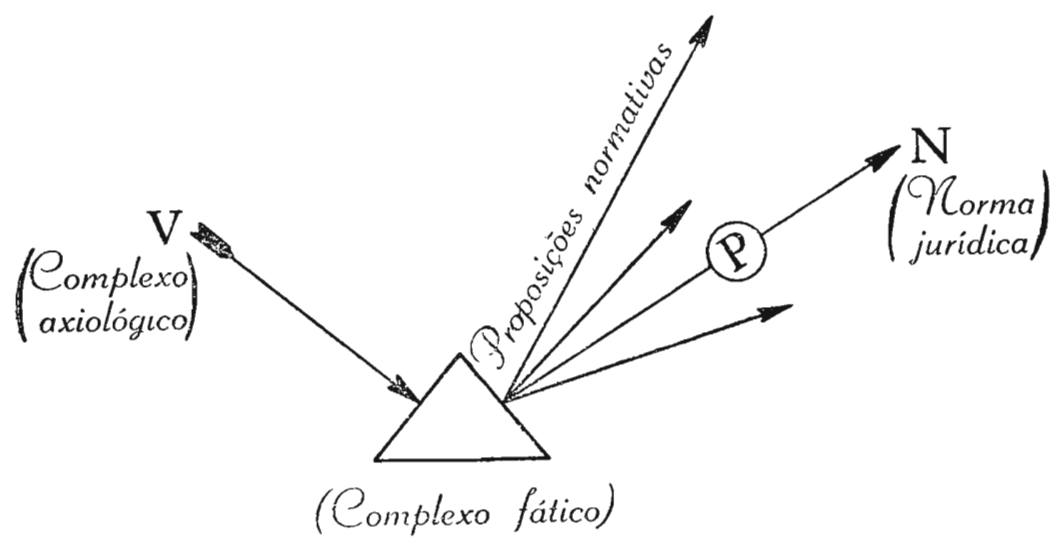


É, repito, a co-participação opcional da autoridade (seja ela a de um orgão legislativo ou judicante, ou ainda a autoridade difusa no corpo social) que converte em norma, armando-a de sanção, uma dentre as muitas vias normativas possíveis. Essa norma é momento de um processo, podendo sofrer alterações semânticas através do tempo. Tais mudanças de sentido, ligadas ao caráter criador do ato interpretativo, equivale a verdadeiras criaçôes normativas, independentes da providência, às vezes tardia ou desnecessária, da revogação parcial ou total da norma originàriamente formulada.

5 - Esclarecer as grandes leis de tendências que porventura presidam ao processo fático-axiológico da nomogênese juridica e de seu desenvolvimento como componente do mundo cultural, constitui tarefa a ser cuidada notadamente pela Sociologia Jurídica, com base na observação direta dos fatos sociais e com os subsídios da Psicologia Social, da Política do Direito, da História do Direito, etc.

Vista a questão sob o prisma da Filosofia do Direito, parece-me, no entanto, possivel discriminar algumas teses fundamentais sôbre tão relevante questão, que põe em evidência a necessidade essencial da análise do Poder na compreensão da origem e do desenvolvimento da norma jurídica:

a) A "nomogênese" jurídica pode ser compreendida como momento de um processo total, o qual, englobando objetivamente cada experiência normativa particular, dar-lhe-ia sentido concreto (concreção do tipo hegeliano, que pressupõe a objetividade de uma idéia, cujo desenvolvimento dialético daria nascimento às experiências particulares, válidas tão sòmente porque e enquanto inseridas no processo histórico total).

b) A tese oposta de cunho relativista, e até mesmo cético, de uma "nomogênese jurídica" atômicamente concebida, insuscetível de ser explicada no conjunto da experiência histórico-social 
do Direito: cada experiência normativa particular seria um mundo "a se", distinto ou desligado dos demais, de maneira que cada norma jurídica teria a sua própria história e validade.

c) A tese que não subordina a nomogênese jurídica à unidade de um processo de atualização de um valor únitário e absoluto, mas, embora reconhecendo a especificidade de cada momento normativo, não o erradica do processo total da experiência do Direito, a qual, por ser uma experiência estimativa, participa da "soḷidariedade" ínsita no mundo dos valores; e, por ser uma "experiência humana", prende-se sempre ao foco irradiante de todos os "valores", que é "o próprio homem visto como valor".

As três posições acima distintas, - às quais correspondem múltiplas colocações subordinadas ou derivadas refletem-se, de maneira permanente e decisiva, em tôda a problemática jurídica, por mais que se queira ‘delas abstrair, a pretexto de fuga de questões metafísicas, apontadas simplisticamente como sendo "sem sentido".

Porque, na realidade, o que tais posições condicionam são três posições fundamentais diversas:

a) quanto ao modo de se conceber o papel ou a função do Poder em geral na nomogênese jurídica, ou seja, no ato de pôr-se "in esse" a norma de direito;

b) quanto ao Poder, em particular, no momento da interpretação da norma vigente;

c) quanto, finalmente, à questão nuclear da justiça de cada decisão singularmente considerada.

Nos limites estritos dêste trabalho torna-se impossível desenvolver amplamente tais questões, mas estou conven- 
cido da necessidade de formular problemas, como êstes aqui propostos, os quais resultam das exigências de concreção ou de socialidade jurídicas, reclamadas pelos chamados anti-normativistas, e que devem ser atendidas, mas sem o sacrifício dos valores de segurança, de certeza e de "racionalidade", essenciais a uma concepção democrática do Direito e do Estado, sob pena de correrem risco as garantias e as liberdades fundamentais do homem, expostas às oscilações e às incertezas de uma livre captação do "jus vivens".

Ficarão necessàriamente implícitas algumas consequências do ponto de vista aqui exposto sôbre a normatividade concreta, no que se refere à delimitação do campo da Lógica Jurídica Formal, assim como com referência aos problemas práticos de interpretação do Direito, eis que o processo interpretativo, de natureza necessàriamente axiológica, é da essência mesma da normatividade. De tal sorte que, se não há norma sem interpretação, também se poderá dizer que a norma vive de sua interpretação, condicionada esta por um complexo objetivo de circunstâncias fáticas e valorativas que transcende os quadros preferênciais do juiz ou do administrador, os quais só podem agir autênticamente enquanto intérpretes dos valores vigentes na comunidade social que representam.

6 - Vejamos, sumàriamente, quais as consequências que, no plano da exegese e da aplicação do Direito, defluem, lògicamente, das três doutrinas fundamentais sôbre a nomogênese jurídica, tais como foram acima distintas.

Se, com manifesto otimismo, se crê que cada norma não constitui senão o elo expressivo de um valor absoluto, o Poder passa a ser tratado como algo de imanente no próprio processo da juridicidade. Uma estranha e inexplicável fôrça presidiria ao processo histórico do Direito: cada experiência particular valeria positivamente, abstração feita de sua validade intrínseca, porque seria momento necessário na sucessão dos eventos, sucessão esta governada por um valor absoluto e envolvente, de tal modo que o que "é" corresponderia sempre ao que "deve ser". Dêsse 
modo, a interferência do Poder dando fôrça a uma norma e repelindo outras normas possíveis, seria, "ipso facto", um ato de racionalidade absoluta. As consequências de ordem prática desta primeira concepção são fàcilmente compreensíveis, quer se pense no Direito como a atualização dos valores dominantes de uma classe, como se proclama no regime soviético, quer se apresente como a expressão objetiva dos valores da Raça ou do Estado, a cujos insonảáveis desígnios estariam confiados os homens e as coisas. Por via de consequência, interpretar uma norma jurídica qualquer seria sempre realizar uma sondagem na finalidade suprema que lhe dá legitimidade, para acolher-se a solução compatível com o programa político em vigor, ficando em um plano subordinado os valores das pessoas e dos grupos naturais.

Se passarmos a considerar a segunda posição, chegaremos, se quizermos ser corajosamente coerentes, à conclusão relativista de Gustavo Radbruch quando nos diz que, não se conseguindo saber o que é o "justo"; e sendo relativos e variáveis os valores da justiça, torna-se necessário que alguém, armado de fôrça, defina e decida, em cada caso, acerca do "jurídico" (Filosofia do Direito, trad. port., São Paulo, 1937, págs. 137 e segs.). Em tal caso é a análise de cada complexo de circunstâncias que dita o caminho a seguir-se. O máximo que se poderá fazer, para evitar-se o arbitrio da decisão (arbítrio de um só, ou arbítrio de muitos, pouco importa) é considerar a nomogênese cada vez mais, realìsticamente, como um problema tẻcnico. Assentado que esteja o programa de vida preferido por uma comunidade (no sentido da democracia individualista, da democracia social, ou do coletivismo, segundo fatôres de natureza meta-jurídica) o Poder, que converte uma "regra possível" em uma norma efetiva, agirá segundo as diversas circunstâncias, em função dos fins gerais e dos meios idôneos. Como diz Roubier, a Política Juridica cederá lugar à Técnica Jurídica, vista essencialmente com uma 
"ciência dos meios", destinada a tornar assimilável pelo corpo social o fim visado. (Travaux de la Semaine Internationale du droit, Paris, 1950, págs. 150 e segs.)

Sempre dentro desta segunda concepção, uma vez posta a regra, como se caracteriza a tarefa do administrador ou do juiz que devem interpretar e aplicar o direito? Ao lado dos que ainda pregam a estrita subordinação de ambos ao modêlo criado pela técnica legislativa, avulta o número dos que, em maior ou menor grau, reconhecem a liberdade do magistrado ou do administrador perante a regra, atribuindo-lhes o dever de repetir, na esfera ou órbita de sua competência, o mesmo trabalho de elaboração técnico-científica já desenvolvido de início, genèricamente, pelo legislador: à luz das circunstâncias fáticas particulares, ao administrador ou ao juiz cabe adaptar a norma jurídica ao que a sua observação dos fatos sugere, guiados por critérios objetivos de ordem cientifica, ou então, preencher as lacunas da legislação sempre seguindo o que the determina uma pesquiza de cunho eminentemente sociológico. Como se về, levando a questão até às suas últimas e rigorosas consequências, - crê-se na possibilidade de respostas para a singularidade de cada caso, embora com base em critérios científicos, que seriam os únicos horizontes delimitadores da ação do intérprete.

De conformidade com a terceira posição acima apontada, - para a qual acabam inadvertidamente convergindo muitos dos adeptos das outras duas tendências, - o que nos revela a experiência histórica do Direito é um desejo de composição permanente entre liberdade e segurança, um renovado esfôrço de implicação entre o particular e o geral, entre os valores de estabilidade e os de progresso, o que explica a "prudência" da qual deve se revestir uma ciência, que desde a intuição sintomática de suas origens, se chama "Jurisprudência"

É preciso, em verdade, não olvidar que, na nomogênese juridica, o Poder representa sempre um momento de livre escolha, um coeficiente de discricionariedade, por mais pre- 
ciosos que sejam os subsídios fornecidos pela Política do Direito, pela Sociologia Jurídica, pela Economia, por tôdas as Ciências que digam respeito à hipótese a ser regulada. Isto ocorre, quer o Direito se origine principalmente no plano legislativo, como nos países de tradição romanística, quer resulte da atividade jurisdicional ou dos costumes, como acontece nos paises da "Common Law": o Poder pode revelar-se através de orgãos definidos (Parlamentos, Tribunais, etc.) ou atuar como fôrça genèricamente difusa no corpo social, como se dá com as normas jurídicas consuetudinárias, quando a opção é o produto de opções anônımas que se repetem e se reforçam através do tempo.

Não sendo a norma jurídica particular considerada a expressão de um valor objetivo supremo; nem tão pouco a expressão genérica de um saber científico verificável em cada hipótese isolada; mas antes a composição prudente de exigências fático-axiológicas, resultante da subordinação dos dados sociológicos, econômicos ou ciêntificos a prudentes critérios de oportunidade e de conveniência, impõe-se a conclusão de que a norma jurídica não pode ser vista, pelo interprete, como um modêlo definitivo: é um modêlo sujeito à prudência determinada pelo conjunto das circunstâncias fático-axiológicas em que se encontra situado o administrador ou o juiz.

Fixemos, por um instante, êste ponto essencial, mesmo porque êle nos esclarece o sentido da normatividade, inserida em um processo histórico-cultural que, pela sua própria estrutura, não pode deixar de se apresentar como "processo de implicação e de polaridade", em virtude de sua natureza axiológica.

A normatividade, como já disse, é momento conclusivo de cada ciclo particular da experiência do Direito, pois uma experiência social, que não atinja o momento da "normatividade", não chega a ser experiência jurídica. É preciso situar bem a questão, pois, muitas vêzes, confunde-se 
o que é culminante no âmbito de um processo particular com o que é decisivo de maneira geral, absolutizando-se, dessa forma, o valor da norma como tal.

Nêste sentido, nunca é demais insistir sôbre a penetrante ponderação de Benjamim Cardozo quanto ao valor provisório de cada norma jurídica: "As normas e princípios existentes podem nos dar a nossa situação presente, o nosso comportamento, nossa latitude e longitude. A estalagem em que nos abrigamos durante a noite não é o fim da jornada. O direito, assim como o viajante, deve estar pronto para o amanhã. Êle deve ter um princípio de evolução". (The growth of the Law, Yale University Press, 1948, págs. 19 e seg)

Essa provisoriedade da norma não deve, todavia, ser entendida formalìsticamente, para indicar o fato óbvio de que não há normas jurídicas que não possam ou não devam, mais cêdo ou mais tarde, ser substituídas por outras mais adequadas à evolução social.

$O$ que se deve antes entender é que a norma juridica mesma, sem que sofra qualquer alteração de ordem formal, isto é, embora mantendo extrinsecamente a sua estrutura verbal, na realidade, é suscetível de contínuas mudanças. Isto ocorre em virtude:

1) da incidência de novas normas que venham exercer pressão sôbre a totalidade do sistema, visto como basta, às vêzes, uma só lei nova para alterar o sentido de muitas outras; a interpretação é sempre de uma norma situada no sistema, o que nos previne contra certas pretensões da Lógica Jurídica formal;

2..$^{\circ}$ da alteração verificada na tábua dos valores da comunidade, a tal ponto que um mesmo artigo de lei, não obstante a identidade verbal, pode significar uma coisa no Brasil e outra bem diversa na Rússia soviética, o que nos pre- 
vine contra identificações apressadas entre os sistemas legislativos feitas por alguns cultores do Direito Comparado;

$\left.3 .^{\circ}\right)$ da superveniência de imprevistas condições técnicas, com mudanças no plano fático, que restringem ou alargam o âmbito de incidência de modêlo normativo.

Não é demais lembrar alguns exemplos de alteração substancial sofrida por certas normas jurídicas, não obstante a inalterabilidade de sua vigência formal.

Estão aí, em primeiro lugar, tôdas as mutações por que passou o velho Código Civil Francês em matéria de responsabilidade civil, notadamente a partir das últimas décadas do século passado, quando os Tribunais, como nota Georges Ripert, foram cedendo aos reclamos da doutrina, aceitando as "construções técnicas" que esta oferecia aos textos imutáveis, em função de elementos supervenientes e imprevistos no conviver soeial. As normas aparentemente eram as mesmas, mas, na realidade, passavam por alterações semânticas tão profundas que teriam provocado justa perplexidade nos mentores da Escola da Exegese.

No Brasil, para não citar senão um caso dos mais expressivos, pense-se nos nobres recursos de exegese da jurisprudência pátria para salvaguardar os direitos hereditários do conjuge superstite, que, segundo o sistema do Código de 1916, estaria, no rigor do texto, sujeito à sua lei pessoal consagradora do regime de separação de bens, acarretando situações de "summa injuria" São todos exemplos de uma alteração na tábua dos valores sociais, pela crescente afirmação da idéia de solidariedade.

Em matéria contratual, enquanto prevaleceu o princípio da "autonomia da vontade", - expressão víva de uma civilização de tipo individualista, - não houve possibilidade de encontrar nos textos de nossa lei civil guarida para 
as soluções que, agora, em outro clima espiritual, cada vez mais se acentuam com o dirigismo contratual e a cláusula "rebus sic stantibus".

Vê-se, pois, que a revogação de uma lei tão sòmente por outra lei é uma verdade no plano formal da vigência, mas não no domínio concreto da eficácia da regra de Direito.

Mudanças de ordem axiológica ou fática podem implicar em alterações semânticas que dão nascimento, em última análise, a uma norma nova quanto a seu conteúdo, o que se torna ainda mais evidente em se tratanto de "standards" jurídicos que permitem a configuração da hipótese normativa à luz da natureza e das circunstâncias do caso, ou segundo critérios que possibilitam ampla margem de estimativa.

Poderiamos dizer, em suma, que a norma juridica, resultante de fatos e valores, uma vez posta em vigor, atua sôbre o meio social, suscitando novos processos axiológicos ou assumindo dimensões axiológicas diversas, pela intercorrência de fatos imprevisíveis. No decurso do tempo, a norma vive em um processo dialético, que possui eficácia nos limites da elasticidade de sua vigência: quando o índice máximo de adaptação é atingido, põe-se, com urgência, o problema da revogação formal.

Isto pôsto, poder-se-ia representar o processo evolutivo do conteúdo de uma norma do seguinte modo:

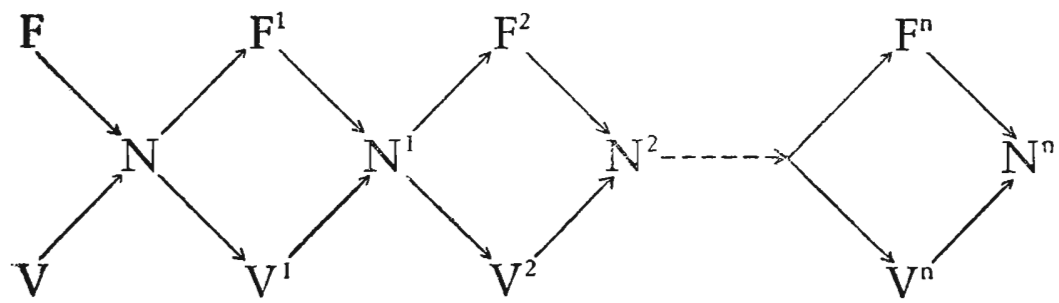


A norma jurídica, por conseguinte, vive inserida na concreção do processo histórico, representando sempre uma medida ou, relevem-me a expressão pouco precisa, uma ponte flexível e elástica entre fatos e valores.

Pois bem, nessa renovada adaptação evolutiva da norma jurídica aos fatos e valores, enquanto ela se mantém em vigor, deve ser respeitado o coeficiente de sua elasticidade natural. À norma jurídica corresponde sempre certo horizonte intrasponível de vigência e de eficácia, dentro do qual é mistér que se mantenha o interprete, sob pena de se comprometer o valor de certeza, que é essencial ao Direito.

Dir-se-á que esta certeza fica comprometida, quer quando o aplicador do Direito se converte em instrumento de um valor absoluto (classe, nação, etc.); quer quando age em nome de supostas verdades cientificas livre e rigorosamente atingidas; quer, ainda, quando procura atender, com prudência, aos dados que a ciência revela sôbre os elementos fáticos, ou ao que a sua consciência apreende no mundo dos valores. Nesta última hipótese, porém, os valores, dos quais o juiz ou o administrador deve ser interprete, não são, os de sua convicção pessoal, os de sua predileção individual, mas sim os valores vigentes na comunidade. Maior segurança seria absurdo pretender, na escala da experiência humana.

Com tal maneira de entender-se a norma jurídica, reconhece-se que ela é sempre a expressão de algo que, transcendendo a pessoa do legislador e a do interprete, aqui e agora, é comum aos que emanam as normas è̀queles a que elas se destinam. Êsse ponto comum de apoio e de referência é dado por algo que possui sentido de permanência no evolver histórico, e que condiciona a história mesma: é a dimensão essencial do homem como pessoa, como valor fonte de todos os valores. 